\title{
CONFLITOS SOCIAIS: IGUALDADE E SOLIDARIEDADE PARA RECONCILIAÇÃO SOCIAL
}

\author{
Josiane Petry Faria ${ }^{1}$ \\ Salete Oro Boff
}

\section{RESUMO}

Pondera-se a respeito da crise de integração social que culmina na relativização de direitos fundamentais e, por conseguinte, do próprio Estado Constitucional. Isso dando especial enfoque ao fenômeno dos conflitos sociais, marcado pelo combate e pela exclusão social de indivíduos, em desrespeito aos direitos de cidadania. Nesse contexto, se apresentam, ao debate, os princípios da igualdade e da solidariedade como articuladores da cidadania, no intuito de viabilizar a co-gestão pública, por meio da democracia deliberativa, na qual os níveis de ação política sejam aceitáveis, de modo que se reconheça o outro e no outro um elo de conciliação social.

Palavras-chave: Conflitos sociais; Democracia; Emancipação social; lgualdade; Solidariedade.

\section{INTRODUÇÃO}

A proposta baseia-se no estudo da participação política e inclusão dos cidadãos, por meio da observância da igualdade e solidariedade, com o intuito de reduzir os níveis de intervenção judiciária nos conflitos sociais com sustentação na ideia de gestão pública compartida.

Parte-se de fenômeno atual de conflito que inquieta e comove a sociedade, direta ou indiretamente. Isso se revela mais fortemente quando se questiona a sobrevivência do Estado Constitucional diante de táticas de exclusão e coisificação de sujeitos. Baseia-se a proposta de estudo na ampliação da participação social nas decisões políticas, valorizando-se 0 procedimento e apresentando como núcleo valorativo a igualdade e a solidariedade.

\section{DOS CONFLITOS SOCIAIS: a complexidade das relações sociais}

A complexidade das relações sociais traz a noção de que é impossível prever os vários aspectos do fenômeno social. Não se pode antecipar as transformações no mundo da vida, sobretudo na sociedade marcada pela desagregação, pelo conflito distante da mesmidade e do círculo aconchegante, como sustenta Baumam ${ }^{3}$, preferindo a fugacidade e a velocidade das relações, marcadas pelo interesse particular e pretensões egoísticas. 
Paoli comenta esse modelo social abordando a ideia de compreensão das ações contra-hegemônicas ao modelo neoliberal, centrando-se, sobretudo, nas possibilidades sociais e políticas do refazer, refundando os vínculos sociais rompidos com a exclusão social. Assim, de modo firme, tece suas críticas ao objetivo econômico4 que visualiza nos cidadãos os importantes consumidores e os trata como tal.

Nessa perspectiva, Baumam descreve a dificuldade da sociedade se comunicar e se solidarizar e, dessa forma, de disseminar os ideais de humanização e do interesse coletivo, "os valores intrínsecos dos outros como seres humanos singulares (e assim também a preocupação com eles por si mesmos) estão quase desaparecendo de vista." ${ }^{5}$

Adverte Fromm que o desejo humano de experimentar união com os outros tem raízes nas condições específicas de existência que caracterizam a espécie humana e é um dos mais fortes motivadores da conduta. ${ }^{6}$ Demonstra 0 autor a necessidade do indivíduo colocar-se na vida social e desenvolver-se socialmente, já que o isolamento não constrói sua maturidade em relação ao outro e nem mesmo com o entorno.

Tanto na sociedade como no Estado, um ponto comum surge no sentido de enfrentar os conflitos sociais, com a construção de relações humanas mais sólidas, respeitando e recuperando os princípios universalistas de justiça, mesmo numa sociedade fundada em valores particulares e egoístas. ${ }^{7} \mathrm{~A}$ proposta, no plano jurídico, está na Constituição, mas, para tal, há de se compreender a necessidade de se efetivar a vivência cidadã. "O que faz com que uma Constituição seja legítima não é sua fonte, senão suas conseqüências. $O$ processo de construção constitucional poscomunista nos ensinará essa lição e isso ocorrerá, ou seja, a legitimação quando der origem a um Estado decente e efetivo." ${ }^{\prime}$ Para Warat, não existe democracia sem dignidade; a democracia é o espaço político da dignidade, referência que vem a calhar com o princípio da solidariedade, que, reconhecidamente, é um reclamo à efetivação dos direitos do homem. ${ }^{9}$ É preciso fomentar a participação política, e o espaço público é propício para articulação da cidadania, não somente como finalidade constitucional, mas, sobretudo, como comprometimento à máxima realização dos direitos fundamentais. ${ }^{10}$

Entretanto, na consecução desses objetivos não se pode ignorar o equilíbrio orçamentário. Compatibilizar a falta de recursos em detrimento à satisfação dos direitos fundamentais torna-se cada vez mais difícil. ${ }^{11}$ Para Leal "os direitos fundamentais deixariam de ser percebidos, fundamentalmente, numa relação meramente vertical Estado/cidadãos, para se conceberem a partir de mecanismos horizontais de garantia e proteção das relações sociais e intersubjetivas." ${ }^{12} \mathrm{Na}$ contemporaneidade isso não é tarefa só do Estado, ${ }^{13}$ mas também da sociedade, para que ganhe força a mudança de atitude e se reescrevam os caminhos segundo princípios comuns.

Neste ponto, ressurge a relação entre direito e política, talvez, na sua versão mais expressiva, isto é, a desconexão da doutrina jurídica com a teoria 
política. Certo é que o efeito globalizante gerou uma profunda modificação política. Reflexo disso é o esquecimento que a normatização dos fenômenos é expressão política, isso na medida em que essa normatização centrada no princípio da legalidade passa a ditar o que se pode e o que não se pode fazer, decisão essa que cabe não ao jurídico, mas sim ao político. Esse alargamento da intervenção judiciária, portanto, uma face ultrapassada do Estado com o encurtamento da democracia. ${ }^{14}$

Em resumo, os conflitos sociais podem ser entendidos na ótica da falta de solidariedade como manifestação do isolacionismo/egocentrismo dos sujeitos e do deslocamento das questões públicas para o âmbito judicial, com medidas de combate que produzem ainda mais conflito.

Para o surgimento e desenvolvimento dos conflitos sociais, inúmeras causas se somam, podendo-se destacar, dentre elas, a ausência de interação do indivíduo com o meio. O que se agrava quando a falta de interação é resultado da falta de implementação dos direitos fundamentais e do acolhimento, eis que a rejeição, a exclusão podem gerar a quebra do vínculo e a identificação do outro apenas enquanto inimigo, sendo que o convívio se torna inviável pelo incremento da violência como forma de relação com os demais. ${ }^{15}$ Veja-se:

Os problema da criminalidade, especialmente 0 de grupos guerrilheiros e a extorsão mediante ameaças de violência, é crônico por todas partes do mundo poscomunista. E resulta claro que, desde o ponto de vista psicológico, os cidadãos perdem interesse nas restrições legais a discricionaridade de polícias armadas letalmente em ambientes de criminalidade intensiva." (p. 147-148)

Bleger $^{17}$ explica que a agressão é um comportamento adaptativo que resulta numa forma ativa de enfrentar as condições ambientais para o próprio desenvolvimento da pessoa e de seus pares. Quanto à violência, é um comportamento destrutivo dirigido contra membros da mesma espécie, em função de sentimentos de inveja pela dificuldade de ver outras pessoas se desenvolvendo.

Completa ele dizendo que as condutas do ser humano são influenciadas por fatores biológicos, ambientais, psicológicos e econômicos. Nesse sentido o homem não nasce nem bom, nem mal. ${ }^{18} \mathrm{O}$ homem apenas nasce e na medida em que suas necessidades básicas são atendidas o seu desenvolvimento saudável é garantido, caso contrário a hostilidade contra o ambiente vai se desenvolvendo. ${ }^{19}$

Contribuindo com a discussão Arendt diz que a violência integra a essência do ser humano, sendo um elemento pré-político. ${ }^{20}$ Importa, no entanto, lembrar que Aristóteles disse ser o homem um animal político, portanto, destinado a viver em sociedade, ${ }^{21}$ embora sua natureza seja beligerante. Como ensina Chevalier, Maquiavel não parte de um sistema filosófico, como fará Hobbes, para explicar a natureza do homem. Incrédulo, ele não se baseia no pecado original e no dogma da natureza decaída. A seu 
turno Maquiavel ${ }^{22}$ concluiu que os homens são ingratos por natureza. Assim, rancor, ódio, vingança e lutas são características naturais. ${ }^{23}$

Nessa medida, considerando a complexidade do debate a respeito da natureza humana e também dos conflitos sociais, reduzir-se a atuação do Estado Constitucional à função jurídica meramente excludente-punitiva, subverte a sua finalidade. A respeito disso Zaffaroni ${ }^{24}$ comenta:

\begin{abstract}
A essência do tratamento diferenciado que se atribui ao inimigo consiste em que o direito Ihe nega sua condição de pessoa. Ele só é considerado sob o aspecto de ente perigoso ou daninho. Por mais que a idéia seja matizada, quando se propõe estabelecer a distinção entre cidadãos (pessoas) e inimigos (não pessoas), faz-se referência a seres humanos que são privados de certos direitos individuais, motivo pelo qual deixaram de ser considerados pessoas, e esta é a primeira incompatibilidade que a aceitação do hostis, no direito, apresenta com relação ao princípio do Estado de direito. (grifos do autor)
\end{abstract}

Observe-se ainda que na teoria política "o tratamento diferenciado de seres humanos privados do caráter de pessoas é próprio do Estado absoluto, que, por sua essência, não admite gradações e, portanto, torna-se incompatível com a teoria política do Estado de direito." 25

Situando a discussão no tempo é possível afirmar que são frustradas as tentativas de fulminar com a separação bipolar de mundo surgida ou evidenciada a partir da Segunda Guerra Mundial. Veja-se que apesar do reconhecimento da complexidade social, por vezes, se insiste na sustentação dual de mundo, isto é, os bons e os maus, vítimas e criminosos, amigos e inimigos, pessoas e não pessoas. Pior que a divisão social em dois blocos é a pretensão de justificá-la com aporte nos direitos humanos e se satisfazer com práticas, que não se pode chamar de estratégia, de "pura contenção estática" 26.

\title{
3. A SOLIDARIEDADE E A IGUALDADE COMO CENTRO DE RADIAÇÃO DA PARTICIPAÇÃO E EMANCIPAÇÃO SOCIAL
}

Pensar sobre um núcleo procedimental de identidade é uma necessidade que se impõe. ${ }^{27}$ Nisso o Estado Constitucional democrático é impensável sem a igualdade e também sem a solidariedade.

\footnotetext{
Pode-se concluir que o Estado Democrático de Direito, pressupondo reciprocamente uma esfera pluralista, legitima-se enquanto é capaz de, no âmbito político-jurídico da sociedade supercomplexa da contemporaneidade, intermediar consenso procedimental e dissenso conteduístico e, dessa maneira, viabilizar e promover o respeito recíproco às diferenças, assim como a autonomia das diversas esferas de comunicação. ${ }^{28}$
}

Desse modo, devem ter a sua defesa potencializada na esfera pública, num processo de reafirmação dos direitos do homem, não como sujeito de direito, mas como ser humano. Portanto, necessário adentrar nos aspectos relevantes da igualdade e da solidariedade em prol de uma efetiva realização 
da cidadania, que se constitui, concomitantemente, em pressuposto para construção da democracia e também resultado do processo democrático, numa relação de interdependência.

Inquestionável é a necessidade do princípio da igualdade para a democracia, todavia, remanescem os debates a respeito de sua significação, eis que nasceu com a finalidade de neutralizar as diferenças. Na perspectiva do Estado Democrático de Direito, no entanto, percebe-se que a igualdade é no sentido jurídico-político de acesso igualitário aos procedimentos jurídicopolíticos do poder democrático, "pressupondo, a desigualdade fáctica e a heterogeneidade de valores e interesses." ${ }^{29}$ Como descrevem Reis e Melo ${ }^{30}$, 0 direito à diferença é essencial para o exercício da cidadania, "a pessoa não é apenas uma individuação da comunidade, não é somente um indivíduo: cada pessoa constitui algo de único, de original e, portanto, encerra limitações e riquezas interiores que as outras não possuam".

\title{
Conforme Neves:
}

\begin{abstract}
A "fundamentalidade" do direito de igual respeito e consideração depende da existência de uma esfera pública pluralista na qual se assente e seja generalizado o respeito recíproco e simétrico às diferenças. Assim sendo, esse direito precisa ser pressuposto para que os sistemas político e jurídico possam institucionalizar o direito ("secundário") de tratamento igual [...] (grifos do autor) ${ }^{31}$
\end{abstract}

Percebe-se que não se refere à igualdade fática, nem mesmo quanto ao conteúdo e extensão de direitos, mas na verdade isonomia de direitos de cada cidadão em face de garantias por procedimentos jurídico-políticos. ${ }^{32}$

Nesse sentido, tanto a igualdade como a solidariedade aparecem como antecipação das regras para a cidadania. A solidariedade surge para otimizar esse processo de integração, isto é, constitui-se na base de transformação das preferências individuais em pretensões coletivas.

Warat concebe a solidariedade como dimensão ética fundamental, pois colocaria os homens diante do conteúdo mais nobre do compromisso com os socialmente excluídos e existencialmente desaparecidos. "Quando se pratica a solidariedade, está-se reconhecendo a existência do outro como diferente, está aceitando-o sem pretender narcisisticamente fusioná-lo com o modelo de homem que o imaginário instituído produz como fantasia tanática". ${ }^{33}$

Depreende-se que, ao mesmo tempo em que se busca a concretização da cidadania, requer-se a observação do espaço solidário na rotina da açãodeliberação dos atores sociais, por isso que "um dos fundamentos da política deliberativa não é simplesmente a oportunidade de manifestação da opinião de cada um, mas a formatação de posições sociais - coletivas- sobre informações e temas focalizados, consensualmente." 34

Leal explica que para Habermas a esfera pública deve ser compreendida primeiro como fenômeno social e depois como rede adequada à comunicação de conteúdos e por fim, como estrutura comunicacional do agir orientado pelo 
entendimento, tendo a ver mais com o espaço social do que co a comunicação cotidiana. ${ }^{35}$ Nesse espaço, é possível elaborar um diagnóstico de realidade muito mais preciso a possibilitar o trato adequado dos conflitos sociais.

A ligação do conformismo e dos pensamentos uniformizados encontra apoio principalmente na ausência e no consequente descrédito da participação política da sociedade, atomizada pelo ativismo judicial com decisões que provocam, cada vez mais, exclusão social. Tanto a solidariedade como a igualdade, compreendidas como núcleo procedimental, limite para as deliberações e ações estratégicas, representam a base procedimental imprescindível para realização da democracia e do Estado Constitucional.

\section{A DEMOCRACIA PARA EMANCIPAÇÃO E TRATAMENTO DOS CONFLITOS SOCIAIS}

Até a metade do século passado, período pós-guerra fria, o desejo pela democracia era o norteador, porém no período pós-Segunda Guerra Mundial, se tentava entender as condições estruturais da democracia naquele momento histórico. Já na atualidade, discute-se a ampliação do plano democrático, ou seja, formas de construção de uma sociedade mais democrática. ${ }^{36}$ Nas discussões teóricas e na pratica política representativa, a democracia participativa tem sido tratada como uma idéia parapolitica e uma atividade política marginal, uma característica desejável, mas não essencial, de uma democracia moderna.Isso se justifica porque a saúde de uma democracia é medida tanto pela natureza qualitativa dos seus padrões de associação quanto pelo caráter formal das suas instituições. A capacidade do Estado é também central para a efetividade da democracia e nesse panorama a cidadania não é um direito, mas sim uma relação. ${ }^{37}$

Ocorre que desde 1989, a democracia tem sido desafiada pelo seu interior. Isto é, desde então se começou a analisar os ideais políticos da democracia e sua realidade e, com isso, foram encontrados muitos problemas que permanecem sem solução. Pode se argumentar que o caminho até a democracia começou, mas que não alcançou seus objetivos principais. ${ }^{38}$

$\mathrm{Na}$ avaliação da democracia nos países em desenvolvimento as análises elegeram o Estado-nação como unidade crítica, Centrando-se em três pontos principais: a) natureza do regime no poder; b) papel dos partidos políticos e de outros atores políticos organizados na esfera eleitoral e c) a forma pela qual as estruturas estatais moldam os padrões de envolvimento e para a investigação minuciosa de padrões e modos de representação. ${ }^{39}$ Portanto, ausente abordagem mais aprofundada das práticas quotidianas democráticas, sobretudo nos campos institucionais subnacionais, onde tanto os agentes políticos formais quanto os informais se envolvem entre si e com o Estado. ${ }^{40}$ Tem-se, portanto, a promoção de uma participação de baixa densidade.

No Brasil, desde a década de 80 a cidadania ocupa um dos centros do pensamento social e político brasileiros. Sua redescoberta é resultado das limitações da política neoliberal, a qual trouxe idéia da desregulamentação 
público-estatal. Nos anos 90 os Estados foram impelidos a abandonar as políticas públicas de atendimento aos direitos sociais o que vinculou a cidadania à distinção entre espaço público e interesses privados e agudizou a questão da exclusão social e política. ${ }^{41}$

O Estado brasileiro, em razão de limitações de ordem orçamentária e gestão, não atende eficazmente a demanda infinita dos direitos fundamentais. Resultado disso é que, muitas vezes, esses direitos são atendidos apenas diante de intervenção judicial, o que se mostra temerário em relação à diminuição da democracia em face do crescimento do Poder Judiciário.

No entanto, vislumbra-se a possibilidade de aplicação do procedimentalismo deliberativo, pois, como referido anteriormente, a cidadania mantém uma relação de interdependência com a democracia, é condição e resultado. Além disso, a experiência da participação política dos movimentos sociais na Índia ${ }^{42}$ demonstra a possibilidade de implementação da democracia deliberativa em países de modernidade tardia como o Brasil.

No estudo dessa transformação, abandona-se a concepção de Estado de Direito, como ideia formalista e unitária da constituição e passa-se a noção de Estado Constitucional o que determina uma reavaliação dos Poderes do Estado como depositários da vontade soberana popular. ${ }^{43}{ }^{44}$ Habermas se manifesta pelo procedimentalismo, onde se valoriza o processo de deliberação em si como relevante: "um processo que envolve negociações e formas de argumentação." Ou seja: "Além disso a criação legítima do direito depende de condições exigentes, derivadas dos processos e pressupostos da comunicação, onde a razão, que instaura e examina, assume uma figura procedimental. $^{45}$

Assim, o procedimento é condição mínima de diálogo. Na política deliberativa, as pessoas, por meio dos direitos de participação e de comunicação, irão influenciar a própria criação normativa, tornando-se parceiros da democracia e parceiros do direito.

O processo deliberativo é em si como um momento emancipatório. Assim, a obsessão pelo momento de ruptura revolucionaria leva a que muitos não percebam o significado dos momentos embrionários de emancipação social que se desenrolam durante a própria luta. ${ }^{46}$

"A deliberação política e a argumentação pressupõem um público relativamente razoável. Requerem um certo grau de instrução e cultura por parte do público, mas constituem elas próprias um processo de educação e treinamento". ${ }^{47}$ Isso reforça o reconhecimento do pluralismo, pois quer-se que as pessoas tenham pretensões diferentes, condição essencial para a discussão pública, tanto que no processo de formação política da vontade coletiva é que as intenções individuais são expressas e influenciam e são influenciadas até o momento da decisão política.

Por esses motivos Hamel sustenta que a proposta de Habermas é uma democracia discursiva por visar uma política humanitária e uma reconstrução 
do direito democrático. A proposta se configura com o diálogo, eis que a intersubjetividade é um diálogo onde as pessoas se colocam abertamente na busca dessa nova racionalidade. ${ }^{48} \mathrm{O}$ arranjo comunicativo resultante da prática dialógica necessita de uma garantia mínima aos cidadãos dos direitos de comunicação e participação.

Para Benhabib, a teoria da democracia deliberativa não é uma teoria em busca de prática; antes, é uma teoria que pretende elucidar, melhor do que outras, alguns aspectos da lógica das práticas democráticas existentes. ${ }^{49}$ Embora ela não concorde com todos os aspectos do modelo discursivo, particularmente a versão orientada em Habermas.

Elster, ao contrário do que afirma Arendt, diz que a posse ou possibilidade de exercer um direito político pode ser mais importante do que 0 exercício real. Embora a discussão e a deliberação, em outros contextos, possam ser fontes independentes de desfrute, a satisfação obtida na discussão política é parasitária da tomada de decisão. ${ }^{50}$ Todavia, a previsão do exercício do direito de participação política é de fato importante, mas não se efetiva pela simples decisão. A emancipação política e social apenas se efetiva por meio da atividade dialógica como atividade da vivência cidadã.

Uma Constituição democrática é um dispositivo capacitador e não limitador, pois tem como finalidade organizar o governo de forma que melhore a deliberação pública. Um povo secular não quer somente o direito de decidir, também quer participar e tomar boas decisões, uma vez que tem conhecimento de que um sistema desse tipo pode ajudar a transformar a vontade não iluminada do povo em vontade iluminada. De modo que a informação e liberdade de expressão peças-chave nessa engrenagem, eis que a equidade procedimental aumenta as probabilidades de que os perdedores cumpram voluntariamente com as decisões do governo. ${ }^{51} \mathrm{Em}$ termos metodológicos é preciso introduzir um novo discurso sobre a democracia e inventar práticas políticas, expandindo a arena de intervenção política muito além das instituições eleitas e dos partidos políticos.

Reafirma-se que uma sociedade civil se caracteriza pelas relações não predatórias entre estranhos. Assim, se todos os atores políticos se vêem no mesmo barco a atitude instrumental até o direito constitucional seria um fator estabilizador, pois sem consideração e respeito universais para novos participantes, não há legitimidade. É preciso repensar o Estado caso se pretenda que tais atores sejam legítimos, pois mesmo que a afirmação acima possa parecer utópica não se pode admitir a construção do Estado a partir da realização de uma guerra que justifique o que pertence e o que não pertence ao Estado e de quem são os direitos. ${ }^{52}$

O exemplo de San José de Apartadó, na Colómbia, mostra que além da produção, a Comunidade de Paz fez com que os moradores redesenhassem também novas referências políticas e fundamentos éticos para a ação em tempo de guerra e adotar decisões individuais e compromissos sociais que os tornaram visíveis e os situaram como interlocutores, atores nacionais e internacionais. Com isso recuperaram a autonomia, soberania e 
autodeterminação para ações e decisões (decidir autonomamente sem sentirse excluído, mesmo não sendo maioria) da comunidade heterônoma. ${ }^{53}$

\title{
CONSIDERAÇÕES FINAIS
}

Os conflitos sociais representam fenômeno complexo e comum na vida social e por essa razão merecem atenção e estudo, no intuito de que se compreende o seu desenvolvimento e se estabeleçam meios de tratamento que respeitem a condição humana em seus múltiplos aspectos.

Desse modo, a ampliação do espaço de deliberação e a promoção de procedimentos adequados de participação política são essenciais. Entretanto, importante não olvidar a imprescindível vinculação do procedimento ao seu núcleo axiológico, ou seja, a igualdade e a solidariedade, a fim de consolidar o caráter descritivo e prescritivo do debate, enquanto fortalecedor da cidadania.

Assim, a necessidade de tratamento dos conflitos sociais, além de não legitimar a aproximação do Estado absoluto, por meio da judicialização da política com medidas imediatistas e de combate, serve de estímulo ao encontro de novas diretrizes para participação e emancipação social com a consolidação da cidadania. Isso implica na criação de espaço público e de metodologias próprias para o entendimento em situações belicosas, de modo que se preserve o núcleo procedimental e se efetive a cidadania e com isso o Estado Constitucional.

\section{SOCIAL CONFLICT: EQUALITY AND SOLIDARITY FOR SOCIAL RECONCILIATION}

\begin{abstract}
Thinking about the crisis of social integration that culminates in the relativization of the fundamental rights and, therefore, of the Constitutional State, giving special attention to the phenomenon of social conflict, marked by the combat and the social exclusion of individuals, in disregard of the rights of citizenship. In this context are introduced in the debate the principles of equality and solidarity as articulators of citizenship, in order to facilitate the cogovernance, through deliberative democracy, in which levels of political action are acceptable, so that it's possible to recognize the other and in the other a bond of social reconciliation.
\end{abstract}

Keywords: Democracy; Equality; Social conflict; Social emancipation; Solidarity. 
1. Doutoranda em Direito pelo Programa de Pós-Graduação Stricto Sensu - Doutorado em Direito da Universidade de Santa Cruz do Sul; Mestre em Direito pela Universidade de Caxias do Sul; Professora da Faculdade de Direito da Universidade de Passo Fundo; jfaria@upf.br.

2. $\mathrm{PhD}$ em Direito/UFSC. Doutora em Direito/UNISINOS. Professora do Programa de Pós-Graduação em Direito - Mestrado da Universidade de Santa Cruz do Sul - UNISC. Linha de Pesquisa: Políticas Públicas de Inclusão Social. Grupo de Pesquisa: Políticas Públicas de Inclusão Social - Subgrupo: Desenvolvimento, Inovação e Propriedade Intelectual.Pesquisadora da Faculdade Meridional-IMED. Professora do Instituto de Ensino Superior de Santo Ângelo-IESA.

3. BAUMAN, Z. La globalización: consecuencias humanas. Buenos Aires: Fondo de Cultura Econômica. 1999, p. 90.

4. No Brasil, soma-se a ambiciosa pretensão de criar uma consciência de cidadania entre o empresariado, igual a uma consciência humanitária ativa, embora a maioria do empresariado silencie, que atue sobre as fontes produtoras da miséria e não intervenha no debate sobre a política econômica. Não precisa mencionar que tal estratégia provoca um enaltecimento do setor privado e descrédito do setor público. PAOLI, M. C. Empresas e responsabilidade social: os enredamentos da cidadania no Brasil. In: SANTOS, B. de S. Democratizar a democracia: os caminos da democracia deliberativa. Rio de Janeiro: Civilização Brasileira, 2002, p. 386; 393.

5. BAUMAN, Z. Amor líquido. Rio de Janeiro: Jorge Zahar, 2003, p. 96.

6. FROMM, E. Ter ou ser? 3. ed. Rio de Janeiro: Zahar, 1976, p. 111.

7. HABERMAS, J. Direito e democracia: entre facticidade e validade. V. I. Tradução de Flávio Beno Siebeneichler. Rio de Janeiro: Tempo Brasileiro, 2003, p. 326.

8. HOLMES, Stephen. El constitucionalismo, la democracia y la desintegración Del Estado. In: KOH, H. H.; SLYE, R. C. Democracia deliberativa y derechos humanos. Barcelona:Gedisa, 2004, p. 149.

9. WARAT, L. A. Epistemologia e ensino do direito: o sonho acabou, Florianópolis: Fundação Boiteux, 2004. v. II, p. 389.

10. HERMANY, R.; TABARELLI, L. O poder local como espaço de articulação da cidadania. In: COSTA, M. M. da; TERRA, R. B. M. da R. Barcelos; RICHTER, D. (org) Direito, cidadania e políticas públicas III. Porto Alegre: Ufgrs, 2008, p. 230.

11. LEAL, R. G. Condições e possibilidades eficaciais dos direitos fundamentais sociais: os desafios do Poder Judiciário no Brasil. Porto Alegre: Livraria do Advogado, 2009, p. 75.

12. LEAL, R. G. O Estado-juiz na democracia contemporânea: uma perspectiva procedimentalista. Porto Alegre: Livraria do Advogado, 2007, p. 50.

13. SANTOS, B. de S.; AVRITZER, L. Introdução: para ampliar o cânone democrático. In: SANTOS, Boaventura de Souza. Democratizar a democracia: os caminos da democracia participativa. Rio de Janeiro: Civilização Brasileira, 2002, p. 67, p. 38-79.

14. HABERMAS, J. Direito e democracia: entre facticidade e validade. V. II. Tradução de Flávio Beno Siebeneichler. Rio de Janeiro: Tempo Brasileiro, 2003, p. 351-354.

15. ANYJAR, L. C. Inseguridad y control. Revista Capítulo Criminológico. Volumen 18-19, Universidad de Zulia, Venezuela, p. 30, 1990.

16. HOLMES, S. El constitucionalismo, la democracia y la desintegración Del Estado. In: $\mathrm{KOH}, \quad \mathrm{H}$. H.; SLYE, R. C. Democracia deliberativa $y$ derechos humanos. Barcelona:Gedisa, 2004, p. 65-171.

BLEGER, J. Psicologia da conduta. 2. ed. Porto Alegre: Martins Fontes, 1989, p 65.

18. ZAFFARONI, R. E. Criminologia: aproximación desde um margen. Bogotá: Temis, 1988.

19. WINNICOTT, D. W. Delinqüência e privação. São Paulo: Martins Fontes, 1987, p. 48.

20. ARENDT, H. A condição humana. 10ª ed. Rio de Janeiro: Forense Universitária. 2005. p. 40

21. ARISTÓTELES. Política. Texto Integral. São Paulo: Martin Claret. 2008. p. 56.

22. CHEVALIER, J-J. História do Pensamento Político. Tomo I. Rio de Janeiro: Guanabara. 1982. p. 266.

23. MAQUIAVEL, N. O Príncipe. São Paulo: Círculo do Livro S.A. s/d. p. 108.

24. ZAFFARONI, E. R. O inimigo do direito penal. Tradução de Sérgio Lamarcão. 2 ed. Rigo de Janeiro: Revan, 2007, p. 18. 
25. ZAFFARONI, E. R. O inimigo do direito penal. Tradução de Sérgio Lamarcão. 2 ed. Rigo de Janeiro: Revan, 2007, p. 11.

26. ZAFFARONI, E. R. O inimigo do direito penal. Tradução de Sérgio Lamarcão. 2 ed. Rigo de Janeiro: Revan, 2007, p. 155-156.

27. Mais adiante se verá que esse núcleo é necessário para impedir que via procedimentose excluia o próprio procedimento.

28. NEVES, M. Entre Têmis e Leviatã: uma relação difícil.São Paulo: Martins Fontes, 2006, p. 156.

29. NEVES, M. Entre Têmis e Leviatã: uma relação difícil. São Paulo: Martins Fontes, 2006, p. 168.

30. REIS, J. R. dos; MELO, M. P. Imigração e relações interculturais no contexto da globalização entre igualdade e diversidade, as novas fronteiras da democracia. In: REIS, J. R. dos; LEAL, R. G. (org) Direitos sociais e políticas públicas: desafios contemporâneos. T. 9, Santa Cruz do Sul: Edunisc, 2009.

31. NEVES, M. Entre Têmis e Leviatã: uma relação difícil. São Paulo: Martins Fontes, 2006, p. 170.

32. NEVES, M. Entre Têmis e Leviatã: uma relação difícil. São Paulo: Martins Fontes, 2006, p. 183.

33. WARAT, L. A. Epistemologia e ensino do direito: o sonho acabou, Florianópolis: Fundação Boiteux, 2004. v. II, p. 388.

34. LEAL, R. G. Demarcações conceituais preliminares da democracia deliberativa: matrizes habermasianas. Inédito.

35. LEAL, R. G. Demarcações conceituais preliminares da democracia deliberativa: matrizes habermasianas. Inédito.

36. SANTOS, B. de S.; AVRITZER, L. Introdução: para ampliar o cânone democrático. In: SANTOS, B. de S. Democratizar a democracia: os caminos da democracia participativa. Rio de Janeiro: Civilização Brasileira. 2002, p. 38-79.

37. HELLER, P.; ISAAC, T.M. T. O perfil político e institucional da democracia participativa: lições de Kerala, Índia. In: SANTOS, Boaventura de Souza. Democratizar a democracia: os caminos da democracia participativa. Rio de Janeiro: Civilização Brasileira, 2002, p. 65. p. 599-642.

38. CASAMIGLIA, A. Constitucionalismo y democracia. In:KOH, H. H.; SLYE, R. C. Democracia deliberativa y derechos humanos. Barcelona: Gedisa, 2004, p. 166. p. 65 171.

39. HELLER, P.; ISAAC, T.M. T. O perfil político e institucional da democracia participativa: lições de Kerala, Índia. In: SANTOS, B. de S. Democratizar a democracia: os caminos da democracia participativa. Rio de Janeiro: Civilização Brasileira, 2002, p. 61-62.

40. HELLER, P.; ISAAC, T.M. T.. O perfil político e institucional da democracia participativa: lições de Kerala, Índia. In: SANTOS, Boaventura de Souza. Democratizar a democracia: os caminos da democracia participativa. Rio de Janeiro: Civilização Brasileira, 2002, p. 61.

41. PAOLI, M. C. Empresas e responsabilidade social: os enredamentos da cidadania no Brasil. In: SANTOS, B. de S. Democratizar a democracia: os caminos da democracia deliberativa. Rio de Janeiro: Civilização Brasileira, 2002, p. 377.

42. SHETH, D. L. movimentos na Índia: para uma nova política de democracia participativa. In: SANTOS, B. de S. Democratizar a democracia: os caminos da democracia participativa. Rio de Janeiro: Civilização Brasileira, 2002, p. 98.

43. LEAL, R. G. O Estado-juiz na democracia contemporânea: uma perspectiva procedimentalista. Porto Alegre: Livraria do Advogado, 2007, p. 46.

44. Neste trabalho não se enfrentará a discussão que envolve teses substancialistas e procedimentalistas.

45. HABERMAS, J. Direito e democracia: Entre facticidade e validade II. 2 ed. Tradução de Flávio Beno Siebeneichler. Rio de Janeiro: Tempo Brasileiro, 2003, p. 09 -121.

46. BUHLUNGU, Sakhela. O reinventar Da democracia participativa na Africa do Sul. In: SANTOS, Boaventura de Souza. Democratizar a democracia: os caminos da democracia participativa. Rio de Janeiro: Civilização Brasileira, 2002, p. 158.

47. MANIN, Bernard. Legitimidade e deliberação política. In: WERLE, Denílson Luis; MELO, Rúrion Soares. Democracia deliberativa. São Paulo: Singular, Esfera Pública, 2007, p. 35. p. 15-45. 
48. HAMEL, M. O Estatuto das Cidades e o princípio da participação popular: uma análise da política deliberativa em Habermas para o desenvolvimento. Revista Jurídica. N. 18. Maringá. p. 143-144.p. 113-144, 2009

49. BENHABIB, Seyla. Sobre um modelo deliberativo de legitimidade democrática. In: WERLE, Denílson Luis; MELO, Rúrion Soares. Democracia deliberativa. São Paulo: Singular, Esfera Pública, 2007,p. 75.

50. ELSTER, Jon. O mercado e o fórum: Três variações na teoria política. In: WERLE, Denílson Luis; MELO, Rúrion Soares. Democracia deliberativa. São Paulo: Singular, Esfera Pública, 2007, p. 246. P.223-251.

51. HOLMES, Stephen. El constitucionalismo, la democracia y la desintegración Del Estado. In: KOH, Harold Hongju; SLYE, Ronald C. Democracia deliberativa y derechos humanos. Barcelona: Gedisa, 2004, p. 145;149-151.

52. HOLMES, Stephen. El constitucionalismo, la democracia y la desintegración Del Estado. In: $\mathrm{KOH}$, Harold Hongju; SLYE, Ronald C. Democracia deliberativa y derechos humanos. Barcelona: Gedisa, 2004, p. 145;149-150. P.65-171.

53. URIBE, Maria Teresa. Emancipação social em um contexto de guerra prolongada: o caso da Comunidade de Paz de San José de Partadó, Colômbia. In: SANTOS, Boaventura de Souza. Democratizar a democracia: os caminhos da democracia participativa. Rio de Janeiro: Civilização Brasileira, p. 243.

\section{REFERÊNCIAS}

ANYJAR, L. C. Inseguridad y control. Revista Capítulo Criminológico. Volumen 18-19, Universidad de Zulia, Venezuela, 1990.

ARENDT, H. A condição humana. 10. ed. Rio de Janeiro: Forense Universitária. 2005.

ARISTÓTELES. Política. Texto Integral. São Paulo: Martin Claret. 2008.

BAUMAN, Z. La globalización: consecuencias humanas. Buenos Aires: Fondo de Cultura Econômica. 1999.

BAUMAN, Z. Amor líquido. Rio de Janeiro: Jorge Zahar, 2003.

BENHABIB, S. Sobre um modelo deliberativo de legitimidade democrática. In: WERLE, D. L.; M., R. S. Democracia deliberativa. São Paulo: Singular, Esfera Pública, 2007, p. 47-79.

BLEGER, J. Psicologia da conduta. 2. ed. Porto Alegre: Martins Fontes, 1989.

CASAMIGLIA, Alberto. Constitucionalismo y democracia. In:KOH, Harold Hongju; SLYE, Ronald C. Democracia deliberativa y derechos humanos. Barcelona: Gedisa, 2004, p. 65 -171.

CASTRO, J. A origem do direito de solidariedade. Rio de Janeiro: Renovar, 1998.

CHEVAlIER, J-J. História do Pensamento Político. Tomo I. Rio de Janeiro: Guanabara. 1982. 
CORREIA, M. O. G. Os direitos sociais enquanto direitos fundamentais. Revista de Direito do Trabalho, São Paulo: Revista dos Tribunais, ano 31, n. 117, p. 151, jan./mar. 2005.

COSTA, M. M. M. da; M., N. B. Diálogos Jurídicos entre o Brasil e Espanha: da exclusão social aos direitos sociais. Porto Alegre: Imprensa Livre, 2008.

COSTA, M. M. M. da; HERMANY, R. O papel do Estado e da sociedade civil na garantia dos direitos humanos e dos direitos de cidadania. In: RODRIGUES, $H$. T.; COSTA, M. M. M. da. (coord.)Direito e políticas públicas II. Porto Alegre: Imprensa Livre, 2008.

ELSTER, Jon. O mercado e o fórum: Três variações na teoria política. In: WERLE, Denílson Luis; MELO, Rúrion Soares. Democracia deliberativa. São Paulo: Singular, Esfera Pública, 2007, p. 223-251.

FROMM, E. Ter ou ser? 3. ed. Rio de Janeiro: Zahar, 1976.

HABERMAS, J. Direito e democracia: entre facticidade e validade. V. I. Tradução de Flávio Beno Siebeneichler. Rio de Janeiro: Tempo Brasileiro, 2003.

Direito e democracia: entre facticidade e validade. V. II. Tradução de Flávio Beno Siebeneichler. Rio de Janeiro: Tempo Brasileiro, 2003.

HAMEL, M. O Estatuto das Cidades e o princípio da participação popular: uma análise da política deliberativa em Habermas para o desenvolvimento. Revista Jurídica. N. 18. Maringá, p. 113-144, 2009.

HELLER, P.; ISAAC, T.M. T. O perfil político e institucional da democracia participativa: lições de Kerala, Índia. In: SANTOS, Boaventura de Souza. Democratizar a democracia: os caminos da democracia participativa. Rio de Janeiro: Civilização Brasileira, 2002.

HERMANY, R.; TABARELLI, L. O poder local como espaço de articulação da cidadania. In: COSTA, M. M. da; TERRA, R. B. M. da R. Barcelos; RICHTER, D. (org) Direito, cidadania e políticas públicas III. Porto Alegre: Ufgrs, 2003.

HOLMES, S. El constitucionalismo, la democracia y la desintegración Del Estado. In: KOH, H. H.; SLYE, R. C. Democracia deliberativa y derechos humanos. Barcelona:Gedisa, 2004.

LEAL, R. G. Condições e possibilidades eficaciais dos direitos fundamentais sociais: os desafios do Poder Judiciário no Brasil. Porto Alegre: Livraria do Advogado, 2009.

deliberativa: $\begin{gathered}\text { Demarcações conceituais } \\ \text { matrizes habermasianas. Inédito. }\end{gathered}$

preliminares da democracia

O Estado-juiz na democracia contemporânea: uma perspectiva procedimentalista. Porto Alegre: Livraria do Advogado, 2007. 
MANIN, B. Legitimidade e deliberação política. In: WERLE, D. L.; MELO, R. S. Democracia deliberativa. São Paulo: Singular, Esfera Pública, 2007, p. 15-45.

MAQUIAVEL, N. O Príncipe. São Paulo: Círculo do Livro S.A. s/d.

MELLO, C. A. B. de. Conteúdo jurídico do princípio da igualdade. 3 ed. São Paulo: Malheiros, 1993.

NEVES, M. Entre Têmis e Leviatã: uma relação difícil.São Paulo: Martins Fontes, 2006.

PAOLI, M. C. Empresas e responsabilidade social: os enredamentos da cidadania no Brasil. In: SANTOS, B. de S. Democratizar a democracia: os caminos da democracia deliberativa. Rio de Janeiro: Civilização Brasileira, 2002, p. 373-473.

REIS, J. R. dos; MELO, M. P. Imigração e relações interculturais no contexto da globalização entre igualdade e diversidade, as novas fronteiras da democracia. In: REIS, Jorge Renato dos; LEAL, R. (org) Direitos sociais e políticas públicas: desafios contemporâneos. T. 9, Santa Cruz do Sul: Edunisc, 2009.

REIS, J. R. dos; LEAL, R. G. Encantos e desencantos em Hobbes e Locke: a Constituição antropofágica do espaço público. In: REIS, J. R. dos; LEAL, R. G. (org)Direitos sociais e políticas públicas: desafios contemporâneos. T. 9, Santa Cruz do Sul: Edunisc, 2009.

SANTOS, B. de S; AVRITZER, L. Introdução: para ampliar o cânone democrático. In: SANTOS, B. de S. Democratizar a democracia: os caminos da democracia participativa. Rio de Janeiro: Civilização Brasileira, 2002, p. 38-79.

SHETH, D. L. movimentos na Índia: para uma nova política de democracia participativa. In: SANTOS, B. de S. Democratizar a democracia: os caminos da democracia participativa. Rio de Janeiro: Civilização Brasileira, 2002, p. 85129.

STRECK, L. L. Hermenêutica (jurídica): compreendemos porque interpretamos ou interpretamos porque compreendemos?uma resposta a partir do ontological turn. In: Anuário do programa de pós-graduação da universidade do rio dos sinos, São Leopoldo: Unisinos, 2003.

URIBE, M. T. Emancipação social em um contexto de guerra prolongada: 0 caso da Comunidade de Paz de San José de Partadó, Colômbia. In: SANTOS, B. de S. Democratizar a democracia: os caminhos da democracia participativa. Rio de Janeiro: Civilização Brasileira.

WARAT, L A. Epistemologia e ensino do direito: o sonho acabou, Florianópolis: Fundação Boiteux, 2004. v. II, p. 389. 
WINNICOTT, D. W. Delinqüência e privação. São Paulo: Martins Fontes, 1987. WOLKMER, A. C. Pluralismo jurídico: fundamentos de uma nova cultura no Direito. São Paulo: Alfa-Omega, 1994.

ZAFFARONI, E. R.Criminologia: aproximación desde um margen. Bogotá: Temis, 1988.

ZAFFARONI, E. R. O inimigo do direito penal. Tradução de Sérgio Lamarcão. 2 ed. Rigo de Janeiro: Revan, 2007.

Recebido para publicação: 26/07/2011

Aceito para publicação: 23/12/2011 